Cite as: Pollack, J. (2009). Multimethodology in series and parallel: strategic planning using hard and soft OR. Journal of the Operational Research Society, 60, $156-167$.

\title{
Multimethodology in series and parallel: strategic planning using hard and soft OR
}

\author{
J Pollack \\ University of Technology, Sydney, Australia
}

\begin{abstract}
This paper examines two distinct ways in which hard and soft operational research (OR) methodologies can be combined, in series and in parallel. Multimethodology in series is acknowledged as the simpler and more common approach. Multimethodology in parallel is identified as having the potential to provide significant benefits to projects in political, changing, or 'wicked' contexts that multimethodology in series cannot. Observations regarding these approaches to multimethodology are examined in light of an information systems strategic planning project in the Australian public sector. Two distinct methodologies were combined in the project: soft systems methodology and project management. These methodologies are based on the soft and hard paradigms, respectively. However, findings in this paper have the potential to be transferred to combinations of other hard and soft OR methodologies.
\end{abstract}

Keywords: methodology; project management; soft systems methodology; planning; government; information systems

\section{Introduction}

This research focuses on different ways in which operational research (OR) methodologies based in the hard and soft paradigms can be combined in practice. Two distinct multimethodological arrangements are discussed, multimethodology in series and in parallel. The vast majority of multimethodology research involves using different approaches in series. This usually involves movement from soft to hard OR, as an initially undefined but stable environment is clarified, allowing practitioners to move from exploration to product delivery. This paper contrasts serial multimethodology with the parallel combination of methodologies, an approach which can provide significant benefits in dynamic and changing environments, which a multimethodology in series cannot.

This paper starts by examining the OR and Systems Thinking literature on multimethodology, before developing the concepts of multimethodology in series and in parallel. Use of multimethodology in parallel is then described in an information systems (IS) strategic planning project in the Australian public sector, set in a 'wicked' and turbulent environment. This project was conducted as part of the project manager's practitioner-research into multimethodology (Pollack, 2005), and this paper is written from the perspective of the project manager and facilitator. Soft systems methodology (SSM) and project management (PM) were used throughout the entire project. These are two distinct methodologies which are based in the soft and hard paradigms, respectively. Research was managed through Action Research using a hermeneutic framework (Gadamer, 1996) for interpretation of research results. Although findings on parallel and serial approaches to multimethodology have been examined using PM and SSM, these results have the potential to be extended to combinations of other hard and soft methodologies.

The prospect of combining SSM with another methodology is not a new one. Munro and Mingers (2002, p 374) found that SSM is the most common methodology used in multimethodology. Combinations of SSM and Systems Dynamics are discussed by Lane and Oliva (1998), while Jackson (1997) and Ormerod (1995a; 1996) have both combined SSM with other methodologies in the context of IS strategy development. Combinations of PM and SSM can also be found in the literature (eg Stewart and Fortune, 1995, p 280; Ramsay et al, 1996, p 36; Liu and Leung, 2002, p 343; Yeo, 2002, p 245). Most of these either focus on the theoretical combination of these methodologies, or use an approach which can be identified as multimethodology in series. Few examples in the literature can clearly be classified as parallel multimethodology. 


\section{Combining methodologies across the paradigms}

The practice of methodologically or theoretically pluralist research is still developing. In 1998 it was noted that '. . we are only just beginning to see attempts at mixing methods ...' (Lane and Oliva, 1998, p 215), and '. . little methodologically pluralist research has been published ...' (Fitzgerald and Howcroft, 1998, p $322)$. Five years later, the situation had not significantly changed, with Mingers (2003, p 233) finding that pluralist research averaged '... only $13 \%$ of empirical papers'. Although the integration of methodologies is seen as possible across the divide between the hard and soft paradigms (Rosenhead, 1997, p xiv), most combinations of methodologies are not reported to cross this divide (Burrell and Morgan, 1979, p 24; Munro and Mingers, 2002, p 378). This is not surprising as few '. . . practitioners or academics become experienced in using both, let alone using both together' (Ackerman et al, 1997, p 49). The time required to develop interdisciplinary conceptualizations can be considerable (Andersen et al, 2006, p 280). However, some researchers believe that it will become more common for practitioners to move back and forth between these approaches (Howick et al, 2006, p 134).

The differences between approaches based on the hard and soft paradigms have been exhaustively covered in the literature. Checkland and Holwell (2004) discuss the philosophical differences, while Pidd (2004a, p 10) discusses the practical and pragmatic differences between these kinds of approaches. Winter and Checkland (2003) also provide insight into how the differences between the hard and soft paradigms have been embodied in methodologies such as PM and SSM. Description of the differences between the paradigms is reasonably consistent in the literature, but there is variation in how the relationship between the paradigms is depicted (Pollack, 2006).

Pidd (2004a, pp 18-19) identifies three different views on how hard and soft OR approaches relate to each other: as completely distinct and incommensurable; as feeding off each other in a pragmatic and eclectic way; or where soft OR approaches are seen as subsuming hard OR approaches. The first of these three views identified by Pidd (2004a) is a popular perspective in the literature. Many authors have commented that the hard and soft paradigms are incommensurable (eg Burrell and Morgan, 1979, p 25; Jackson, 2000, p 26). Miles (1988, p $55)$ also notes that '... there are those who consider that these two schools of systems thinking are, in practical terms, incompatible'. However, it is '. . important to realize that 'pure' hard and soft approaches are extreme points on a spectrum and that points in between do exist—-thus, some of the aspects discussed are stereotypical at times' (Pidd, 2004a, p 10). Although statements about the tendencies associated with the hard or soft paradigms may be useful didactic simplifications, in practice many methodologies will occupy a 'middle ground' where commensurability and compatibility are possible. This paper takes the second position identified above, assuming that the two paradigms take different, but not incompatible, perspectives on the world.

It has also been noted that the connections between paradigms and the methodologies, methods, tools and techniques often associated with them need not be close (Jackson, 1999, p 17). Techniques or whole methodological stages are often detached from a methodology and are then put to the service of a different methodology from the same paradigm (Mingers and Brocklesby, 1997). Furthermore, there may be no compelling reasons why the use of tools and techniques should not be informed by a different paradigm to that which spawned them (Brocklesby, 1997, p 193). Approaches can actually be detached from their original paradigm and used, critically and consciously, to support different forms of logic (Midgley, 1997, p 272; Mingers, 1997, p 14; Mingers and Brocklesby, 1997, p 498). For instance, a positivist tool might be incorporated into an interpretivist study (McQuinn, 2002, p 385). Flood and Romm (1997) refer to this kind of practice as the 'oblique use' of a method. This kind of approach to multimethodology can be thought of as moving up or down one of the vertical axes in Figure 1.

However, both the hard and soft paradigms can provide valuable insight into a situation, and relying only on one may unnecessarily limit a project. In discussing total systems intervention (TSI), Flood and Jackson (1991) comment that the paradigm governing a project can be consciously chosen, instead of following on from unquestioned assumptions. 'One 


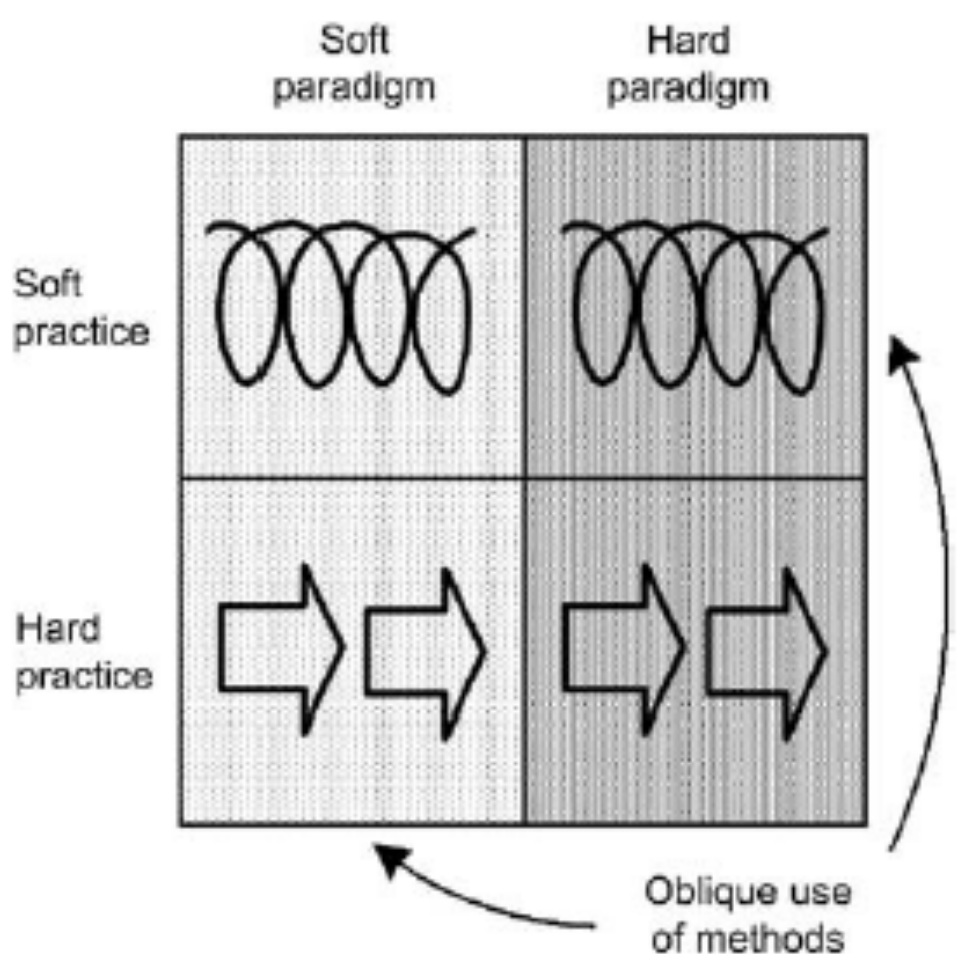

Figure 1: Combination of paradigm and practice methodology,

encapsulating the

presuppositions of a particular paradigm, is granted "imperialistic" status-but only temporarily; its dominance is kept under continual review' (Jackson, 1999, p 16). Other approaches are given a secondary status and operated under the guidance of the temporarily dominant paradigm. As the needs of the situation change, the dominant/secondary relationship between approaches and their paradigms becomes something which can also change. Paradigms, methodologies, tools and techniques can potentially all change throughout a project as the needs of the project develop. The

relationship between paradigm and practice may vary multiple times within a single project, with movement being possible along both horizontal and vertical axes in Figure 1.

\section{Grafting and embedding}

Miles $(1988 ; 1992)$ also provides insight into multimethodology, identifying two models of the combination of hard and soft methodologies: Grafting and Embedding. Grafting (see Figure 2) involves attaching a soft approach onto hard practice, allowing for a situation typified by social complexity to be transformed into a problem suitable for hard approaches (Miles, 1988, p 56). A methodology such as SSM could be used to clarify a situation, before a hard methodology is used to implement the defined system (Gammack, 1995, p 162). Grafting is fundamentally based in the hard paradigm, with the soft methodology

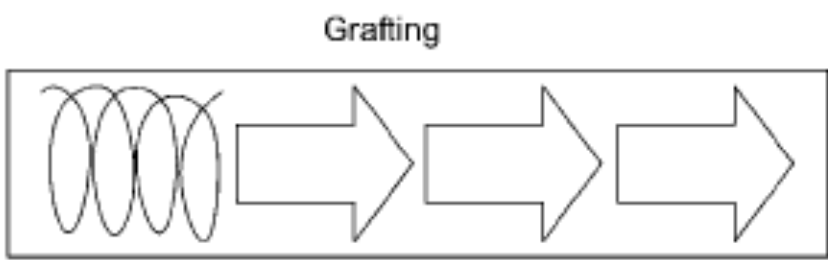

Embedding

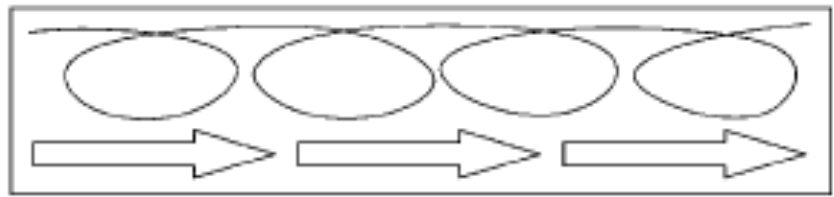

Key Soft methodology $\infty 000 \quad$ Hard methodology $\Rightarrow \Rightarrow$

Figure 2: Grafting and Embedding (based on Miles, 1988).

being put to the service of the hard methodology. Grafting has been identified as the simpler model for combining hard and soft approaches (Miles, 1988, p 59; Taylor et al, 1998, p 432). However, some authors have raised concerns regarding Grafting, such as possible distortion of the methodologies used (Jackson, 1997, p 219), the feasibility of a paradigm shift within the intervention (Zhu, 2000, p 199), and the difficulty of relying on a single person doing justice to both the hard and soft paradigms in a Grafting intervention (Ormerod, 1997, p 52). 

soft OR. Journal of the Operational Research Society, 60, $156-167$.

Miles contrasts Grafting with Embedding, which involves '. . . two interrelated levels of methodological operation ...' (Miles, 1988, p 57). A soft methodology, such as SSM, is used to continuously explore and learn about the problem situation, while a hard methodology is used to facilitate implementation or product delivery. Embedding is a fundamentally soft approach, with the application of hard methods directed by soft inquiry. Embedding can underpin '. . . a sustained collaborative relationship . . .' between participants by enabling ' . . the investigative thrust of a "soft" systems approach to be operated whenever and for as long as its users deem it profitable to do so ...' (Miles, 1988, p 59), instead of ending the focus on collaboration with the transfer from soft to hard approaches. Embedding can promote learning in the latter stages of a project (Ormerod, 1997, p 50). It has been found that practitioners also experience less difficulty swapping between paradigms with Embedding than with Grafting (Ormerod, 1997, p 52).

Grafting and Embedding can also be related to Figure 1. Grafting can be thought of as multimethodology exclusively on the right of the matrix, while Embedding remains on the left of the matrix. This classification is based on their fundamental alignment with either the hard and soft paradigms. The differences between Grafting and Embedding have been recognized by a variety of authors (eg Avison et al, 1998, p 455; Rose and Meldrum, 1999, p 3; Calway, 2000, p 123; Holwell, 2000, p 790; Mathiassen and Nielsen, 2000, p 244; Zhu, 2000, p 187; Champion and Stowell, 2002, p 273; Oura and Kijima, 2002, p 79; Rose, 2002, p 250). However, few authors make more than passing mention of these different ways of combining methodologies. With the notable exception of Ormerod (1995b), very few cases appear in the literature which explicitly identify themselves as examples of Embedding.

\section{Serial versus parallel multimethodology}

Learning regarding the oblique use of methodologies and Miles' (1988) models of Grafting and Embedding can be combined to distinguish between two general multimethodological forms, multimethodology in series and in parallel. The most common way of combining hard and soft OR methodologies is in series. This is generally a movement from soft to hard approaches in a project, and is how serial multimethodology has been depicted in Figure 3. A variety of authors acknowledge this as a potential way of combining approaches (eg Zhu, 2000, p 199; Midgley et al, 2000, p 72). This way of combining approaches has also been called 'front-ending' (Rose, 1997, p 264). For instance, SSM is often viewed as '. . ' 'front-end' analysis ...' (Bond and Kirkham, 1999, p 244), before a different approach is used to manage delivery. There is also a tendency for research to flow from qualitative to quantitative techniques (Kaplan and Duchon, 1988, pp 574-575; Fitzgerald and Howcroft, 1998, p 322), or from inductive approaches to deductive hypothesis testing (Patton, 1990, p 46). Indeed, serial movement from soft to hard approaches is common, and examples abound (eg Avison and Wood-Harper, 1990; Turner and Cochrane, 1993; Neal, 1995; Lai, 2000; Howick et al, 2006, p 113).
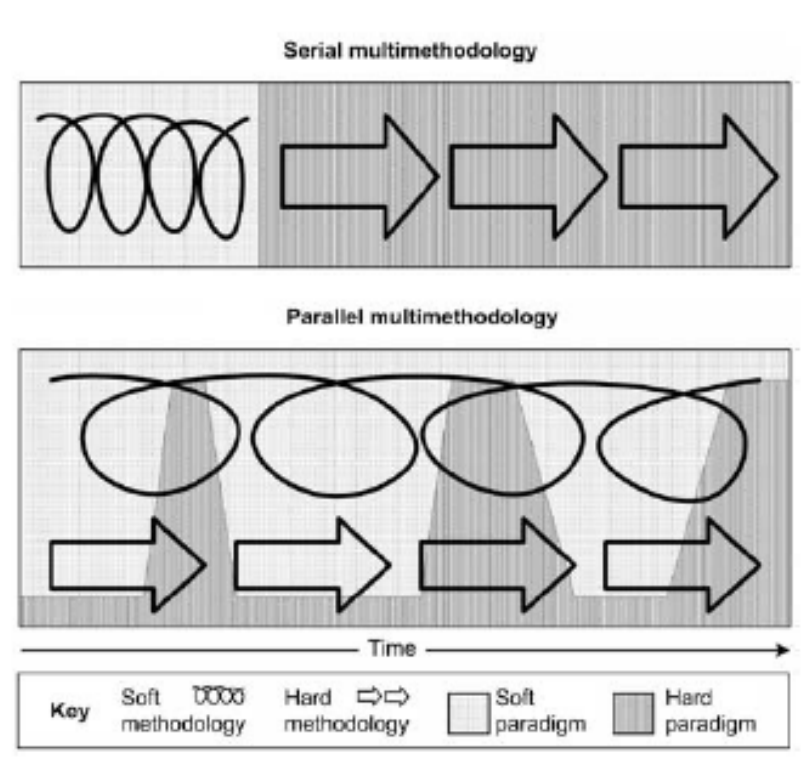

However, multimethodology in series does not have to involve a movement from soft to hard. Examples can also be found where hard OR is used as a precursor to soft OR (eg Pidd, 2004b, p 200; Brown et al, 2006). It would also be possible to use two different methods obliquely and in series. As such, what distinguishes serial multimethodology from parallel is not which methodology or paradigm leads, but that methodologies are used in sequence, one after the other, and that a paradigm change occurs during the project. This may be marked by a significant phase change or reaching a major milestone. A further distinguishing characteristic is that,

Figure 3: Parallel and serial multimethodology 
unlike Miles' model of Grafting, no paradigm is presumed to have fundamental dominance in either serial or parallel multimethodology. Instead, the dominant paradigm is related to the needs of the context and participants.

The parallel model of multimethodology involves using hard and soft methodologies simultaneously. In the case study described later in this paper, the project team used both PM and SSM throughout a project, from project initiation to sign off. Similar to Embedding, parallel multimethodology allows a collaborative and facilitative approach to be sustained throughout the whole project, emphasizing continuous learning and adaptation to change, while a hard approach is used to analyse specific aspects of the situation, develop conclusions or deliver project products. For instance, this approach could be used to continuously refine project objectives and explore alternatives, while potential solutions were being developed. At times during a project, the emphasis may shift to hard or soft OR, but this happens on the understanding that the emphasis will shift again as the needs of the context change. In complex, political or contested contexts an investigative level of soft inquiry could be maintained throughout the project, allowing the practitioner to quickly apply hard OR techniques to address specific issues as appropriate.

Just as the tools, technique and methods may be varied by the practitioner to suit the immediate needs of the situation in parallel multimethodology, so too may the paradigm which informs action. A change in paradigm can also be independent of any change in the tools, techniques or methods used. For example, the technique of Conceptual Modelling in SSM may be used in an project initially under the soft paradigm as an aid to facilitation, but later used under the hard paradigm as a way of describing the 'reality' of the situation. Similarly, a statistical technique may be used under the hard paradigm as a way of predicting stock flows, but then used as the basis for debate and exploration of participant perspectives if differences in stakeholder understanding had become apparent. The hard and soft paradigms represent different perspectives that can be brought to a project, and a parallel approach to multimethodology allows for the practitioner to take advantage of the differences between these perspectives, by testing insight gained with one under the lens of another. This is similar to 'triangulating' research results using multiple methods.

An application of parallel multimethodology may not necessarily have clearly identifiable points at which transition between approaches occurs. Instead, it can involve a dynamic flexibility, where hard and soft techniques and the hard and soft paradigms all have varying influence throughout the project, resulting in a regular movement between the different boxes depicted in Figure 1. Changes in the influence of the dominant paradigm during the project have been interpreted in Figure 3 as variations in the background shading.

Parallel multimethodology is considerably less common, but some cases do stand out. For instance, a parallel approach to multimethodology was reportedly used to great effect in exploring the UK personal taxation system (Pidd, 2004b, p 200; Brown et al, 2006). Andersen and Richardson comment on the need to alternate between divergent and convergent approaches (1997, p 111). Ackerman et al (1997) described a project where hard and soft modelling approaches were combined to create a model of the impact of delay on a megaproject, while Belton et al (1997) described the parallel combination of approaches in a strategic planning workshop in the UK National Health Service. It is interesting to note that the in latter case, the project was designed to be serial, but in application became parallel in response to the needs of the context.

\section{The methodologies}

PM and SSM are two methodologies that have a considerably different areas of focus, and have been developed for use in substantially different practice environments. SSM can, rather uncontentiously, be considered to be based in the soft paradigm. SSM is often considered to be a problem structuring methodology, suited to addressing 'wicked' problems. Very generally, 'SSM defines a process through which its users inquire into purposeful human activity by means of systems ideas ...' (Mathiassen and Nielsen, 2000, p 243) to bring about some change in a situation that will be seen as an improvement (Checkland and Scholes, 1990, p 286). This is often achieved by facilitating definition of what counts as culturally 
feasible and technologically desirable improvement for a particular group (Checkland and Holwell, 1998, p 160). The basic criterion for success in 10 using SSM is ' . . that the people involved felt that the problem had been 'solved' or that the problem situation had been 'improved' or that insights had been gained' (Checkland, 1981, p 146). SSM's '. . . systemic nature makes it suitable for dealing with complex human situations, and it can explicitly cope with differing stakeholder views ...' (Rose and Haynes, 1999, p 208).

PM is typified by markedly different assumptions, processes and techniques to those in SSM. In this case, PM refers to a specific, although diffuse and developing, methodology, strongly influenced by the Project Management Institute and its Guide to the Project Management Body of Knowledge (PMI, 2004). Traditional PM has a long history of engagement with OR through common techniques such as the Program Evaluation and Review Technique and the Critical Path Method. The general tendency in traditional PM is to assume that goals are clear and predefined (Hobbs and Miller, 2002, p 42). Changes to project objectives are discouraged once agreed (Thomas and Tjader, 2000, p 5), with the emphasis being on efficient delivery of products to success criteria which are usually defined in terms of time, cost and quality specifications. There is a strong trend towards the idea of control (Remington and Crawford, 2004, p 3), with the field having been linked to both positivist and realist philosophies (Cooke-Davies, 2000, p 17). PM ha been influenced in its development by Systems Engineering, Systems Analysis (Yeo, 1993, p 111) and the hard paradigm (Winter and Checkland, 2003). Pidd (2004a, p 7) describes traditional OR techniques as very effective in situations involving common situational logic, but less useful in messy situations. These observations also apply to traditional PM.

\section{Strategic planning at HPRB}

SSM and PM were combined in parallel in the context of an IS strategic planning project at the Health Professionals Registration Boards (HPRB). HPRB was part of the public sector in New South Wales (NSW), a state of Australia. The organization was operating within the context of increasing emphasis on electronic service provision within the NSW public sector (eg Office of Information Technology, 1997; NSW Premier's Department, 2000, 2002b; NSW Audit Office, 2001; NSW Health, 2001). There was also a strong emphasis on IS investment as a way of saving money through shared provision of IS and other services (eg NSW Premier's Department, 2002a).

The need to effectively plan IS development was consistently recognized across Government, with agencies required to develop strategic plans for IS infrastructure (NSW Audit Office, 2001, p 11; NSW Health, 2001, p 1; NSW Premier's Department, 2002b, p 1). Plans were to take appropriate account of $\mathrm{PM}$, as '. . . experience suggests a possible wasteland of future e-government failures unless steps are taken to improve project and risk management in agencies' (NSW Audit Office, 2001, p 36). In response, an IS Strategic Development Portfolio of interconnected projects was initiated by HPRB. This paper focuses on one of the projects within the Portfolio, the main deliverable for which was an IS Strategic Plan. This plan was to act as the basis for internal debate on organizational IS development needs over the next 5 years. The project was to be managed over 1 year, concurrent with the initiation of other projects and participants meeting the standard duties of their positions.

SSM, PM and Action Research were used in this project because the project manager and the portfolio manager were both familiar with these approaches, and because of their appropriacy to the context. Action Research was chosen as the basis for managing research findings, due to its combined emphasis on reflection in action and practical outcomes for participants. Other researchers (eg Belton et al, 1997, p 116) have also found Action Research to be appropriate for conducting research on the use of multiple approaches. Data were captured through a combination of meeting, facilitation and interview records, organizational documentation, and reflective diaries. As this study involved an ongoing interaction between application in practice and theory generation, the research questions evolved throughout the research. Methods of data capture were likewise evolved to match the research questions. This was accompanied by explicit examination of the interpretive frameworks which were influencing question formation, data selection and interpretation. The reliability of the study was confirmed through both continuous and long term evaluations, and 

soft OR. Journal of the Operational Research Society, 60, $156-167$.

through contribution to peer-reviewed conferences and publications. A thorough account of these issues is provided elsewhere (Pollack, 2005).

At the start of the project a great deal of time was spent listening to participants, letting them express significant aspects of the situation. Participants developed rich pictures of the environment. Project briefs were developed, identifying goals and strategic linkages, and milestones for the project were defined with senior stakeholders. It quickly became clear that the project was set in the context of considerable environmental uncertainty, which was to make the planning process problematic. Contextual influences included across-Government service delivery initiatives, strategic restructuring within NSW Health, and the likelihood that significant Legislative changes were soon to be passed through Parliament. In response, planning had to accommodate the possibilities of both an increase in the demand for in-house provision of IS services, significant outsourcing and the need to adapt existing process to meet external requirements. In addition, there was a strong possibility that the organization would relocate during the life of the project.

It was agreed with senior stakeholders that a high level of participation was important in ensuring benefits would be realized from the project. Participation varied throughout the project, involving upper management, portfolio and other project personnel, finance, IS, data entry, clerical and administrative personnel, and representatives from related organizations within NSW and other states. Many participants had highly detailed, but localized knowledge, dependent on personal engagement with the organization.

Previous studies have found that IS metaphors can unnecessarily dominate discussion and disempower participants (Day, 2000), making it necessary to mitigate against a focus on IS dominating strategy development (Ormerod, 1995a). It was necessary to mitigate against this at HPRB, as suppliers tended to rely on industry-specific terminology, while internal stakeholders relied on a distinct 'Government' mode of expression. Neither internal stakeholders nor suppliers were familiar with the others' idiom. Other researchers have found that '. . . apparently small differences in vocabulary often foreshadow large differences in world views ...' (Andersen and Richardson, 1997, p 115). In this project, unreflective language use often acted as a barrier to understanding and collaboration. In response, the role of project manager often became that of a translator, negotiating meaning between stakeholder groups.

The approach to managing the project involved simultaneously progressing multiple options for development, some of which represented different means of reaching similar ends, and some of which would be potentially incompatible. There was considerable overlap between development streams. For instance, at one point work based on the hard paradigm mapping the network architecture for one option was brought to a halt because of limits to participant availability and uncovered gaps in understanding. This work was directly followed by negotiating conceptual models for a different option with different stakeholders, now working under the soft paradigm. Paradigm changes were in response to the demands of the work being performed at that time, while development of options was based on participant availability and contextual stability. Although implementation and development of any one solution was slow, because finite resources were being spread across many areas of development, progressing multiple avenues simultaneously allowed for development possibilities to be seized when opportunities eventuated. Figure 4 represents a summary of the processes running throughout the project. What is significant here is that the project could not be divided into phases or tasks, but was typified by ongoing processes. Hassen (1997, pp 279-281) has previously identified that bureaucratic, as opposed to technical, projects are apt to change, and tend to be typified by continuing processes managed in a political environment rather than by discrete tasks. These observations were true for this project.

A Project Management Information System (PMIS) was introduced to HPRB and helped to structure project activities and engage stakeholders, acting as reference point, against which project goals, scope, risks and interdependencies between options could successively be defined. The PMIS could be categorized as a Group Support System, based on the definitions discussed by Ackermann et al (2005, p 308). The PMIS was previously developed by researchers at the University of Technology, Sydney, and refined through a variety of 
Cite as: Pollack, J. (2009). Multimethodology in series and parallel: strategic planning using hard and soft OR. Journal of the Operational Research Society, 60, $156-167$.

NSW public sector projects (eg Costello et al, 2002; Crawford et al, 2003; Pollack et al, 2006) and the research in this paper is indebted to that stream of practitioner research.

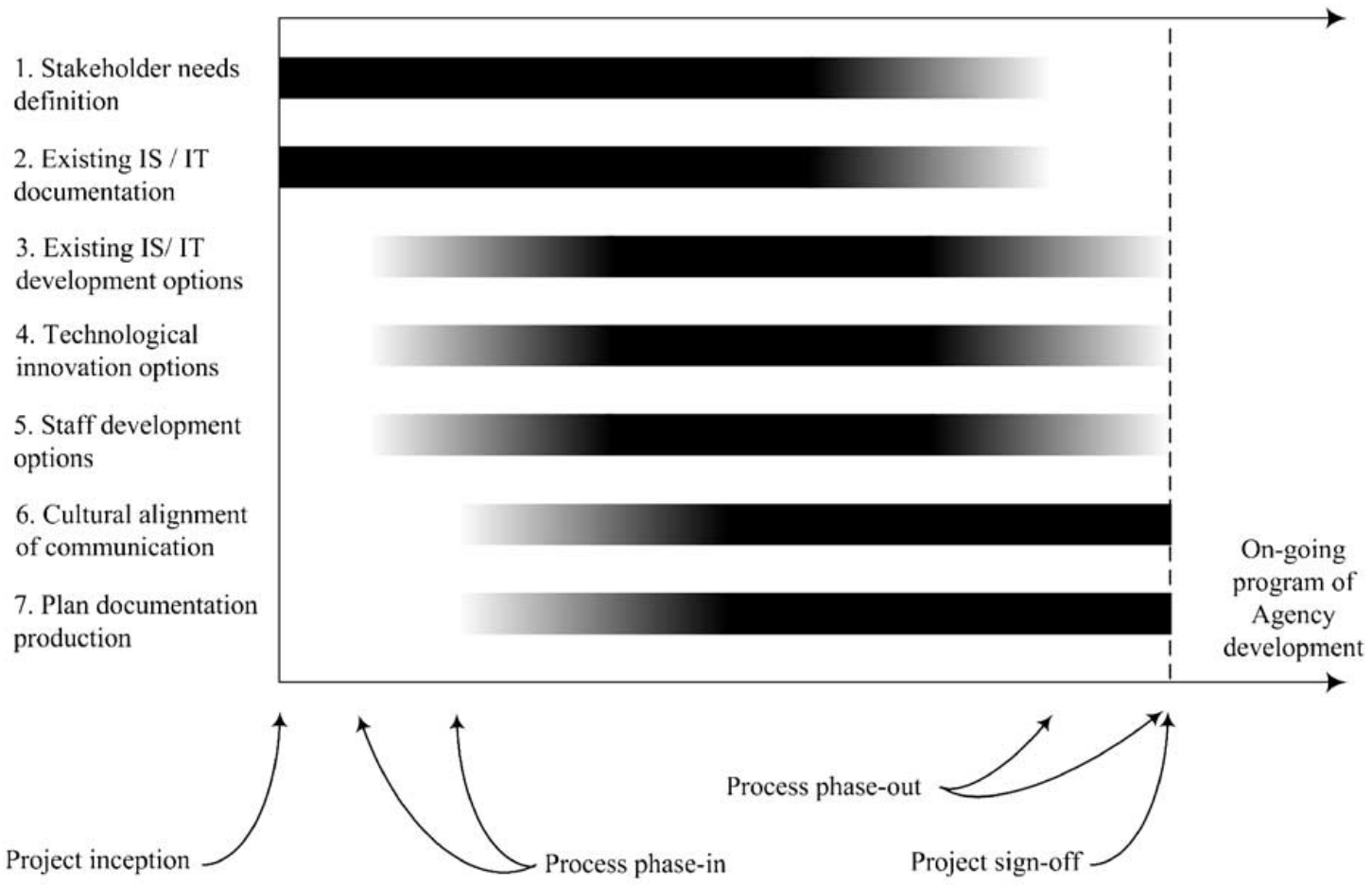

Figure 4: IS/IT Strategic Planning Project timeline

As project goals and success measures were initially only defined at a general level, the project team had room to move as the project developed. Standard PM techniques such as Milestone Planning and Risk Matrices also proved useful throughout the project, as a way of defining a necessary sequence of deliverables at a general level, without making unfounded assumptions. Continuous involvement of upper management and the portfolio manager meant that these could be defined as the project progressed. Variations of Root Definitions and Conceptual Models were also created for each of the options being pursued in the Strategic Plan. Ongoing and iterative modelling and definition of strategic options were central to the project.

PM and SSM were used throughout the project, but not as a clear progression of stages as described in the PMBOK® Guide (PMI, 2004) or the seven-stage model of SSM (Checkland, 1981). The way in which these methodologies were used was not predetermined, and the specific techniques used were selected as the project progressed. A variety of techniques were used for short periods throughout the project; however, the results from techniques were rarely 'finalized'. Work regularly needed to be revisited when environmental influences changed or when new information came to light. For instance, stakeholder analysis flowed into rich picture development, which led to conceptual modelling, defining the project brief and creating root definitions. This may then have led to further conceptual modelling, stakeholder analysis and project brief definition. The order in which techniques were used was less significant than that they were applied in response to the immediate needs of the context and stakeholders. Milestone planning was one of the few techniques that did not require ongoing rework. Milestones were defined at a general level at the start of the project and proved to be a useful planning technique for a turbulent environment, as Turner and Cochrane (1993, p 98) have previously identified.

Nearly 1 year after the project started the majority of influential contextual uncertainties stabilized in the short to medium term. This moment of stability allowed the project team to select the most appropriate among the many options that had been progressed. Without the preparatory work of progressing multiple options, the project team would not have been in a 
position to take immediate advantage of the momentary stability. As the HPRB project neared completion, an increasing portion of the time of the project team was devoted to initiating other projects in the IS Strategic Development Portfolio and projects following on from strategies developed in the plan. The project could be considered to have ended on official handover of the major deliverable (the IS Strategic Plan). However, strategy definition flowed seamlessly into IS implementation and development, with no obvious point of project phase transition.

As the real benefit of strategic planning can only be seen in future changes to the organization, evaluation of this project was conducted 1 year after completion of the 5-year strategic plan. At the time of evaluation, three of the eight strategies detailed in the strategic plan had been successfully completed, with another well underway. Considerable evidence of IS development could be seen within the organization. Overall, the project was considered to be a success by both the Director of HPRB and the portfolio manager. Two years after completion, five of the eight strategies had been completed, and two strategies were currently under development, with the last strategy on hold pending developments in external agencies. Although the successful implementation of strategies following the strategic planning at HPRB cannot be directly linked to the use of parallel multimethodology, these results support the findings of other researchers (Sachdeva et al, 2007, p 160), who found that combining methodologies across paradigms leads to increased implementation of study results in practice.

\section{Modelling HPRB}

Andersen and Richardson (1997) have commented that group model building is becoming increasingly significant within some systems thinking communities. They also provide insight into how this process can be facilitated. Model building with stakeholder groups formed a significant part of project work at HPRB. Models acted as a lingua franca, something which was accessible to end users, management and IS professionals. Pidd (2004a, p 2) distinguishes between two broad kinds of OR models: models used for routine decision making, which constitute the majority of OR models; and models which represent insight for debate. The models used in this project were the latter kind.

Daily modelling practice in the project team changed as modelling progressed. Early on, the majority of communication had been through dialogue, with previously prepared diagrams used as the focus of discussion. As the project progressed, diagrams were more frequently actively drawn during discussion with participants, as a way of mutually developing understanding. Reflection on this led to an understanding of two different ways in which soft modelling can facilitate debate. In the first view, diagrams are seen as an aid to discussion, with the meaning of a separately developed diagram being the focus of discussion. In the second view on soft modelling, discussion becomes intertwined with the modelling process. Participants actively model, while the situation is being debated. Debate and the modelling process become simultaneous. Models become a product of a communication process, while modelling is part of the communication process. The process of modelling in the project naturally and unconsciously moved from the first kind of soft modeling to the second as the project team's experience grew.

As previously mentioned, strategic planning at HPRB was to act as the basis for ongoing internal debate on organizational IS development needs. As such, it was important that communication was readily accessible to participants. Others have noted the importance of providing results that are recognizable to participants (Sachdeva et al, 2007, p 160).

Furthermore, when unfamiliar forms of communication are introduced '... every individual in the group spends an immense amount of energy learning a new iconography or vocabulary for discussing the problem under study' (Andersen and Richardson, 1997, p 114).

Modelling of the project and the various strategies was based on SSM Conceptual Models. However, in order to facilitate understanding and acceptance of the IS strategic plan, models were drawn to look similar to Data Flow Diagrams. Mingers (1995, p 27) has noted that there are '. . . strong resemblances between a conceptual model and a DFD: the conceptual model shows activities and the logical links between them while the DFD shows data flows and the 
activities that transform one into another'. These similarities were used to create Conceptual Models depicting systems of human action, informed by an interpretivist epistemology, but presented as Data Flow Diagrams, a form of modeling which was familiar to some key participants and therefore not as likely to meet with resistance. As a result, models were recognizable to participants, and there was no need for participants to learn a new iconography. An alternative way of interpreting this is that Data Flow Diagrams were used obliquely, under the soft paradigm.

\section{Changing paradigms}

Psychological barriers to swapping between paradigms have often been raised in the literature. Such barriers relate to the '... problems of an individual agent moving easily from one paradigm to another' (Mingers, 1997, p 13). The potential for a practitioner to adopt pluralist practice has been said to be heavily influenced by their previous experience (Brocklesby, 1997, p 203; Mingers and Brocklesby, 1997, p 507; Munro and Mingers, 2002, p 369). Tendencies have been identified between personality types and paradigms (Wolstenholme, 1999, p 423; Mingers, 2003, p 246), and that an individual's fundamental world views may cause obstacles to operating within certain paradigms (Mingers and Brocklesby, 1997, p 499). It has been suggested that two facilitators may be needed in order to overcome practical difficulties in using the hard and soft paradigms concurrently, with one facilitator versed in each paradigm (Belton et al, 1997, pp 128-129).

In contrast, in this project frequent swaps were made between the hard and soft paradigms by a single practitioner with little apparent difficulty. Practical problems in changing between approaches did not relate to matters of their incommensurability, but related to the difficulties in maintaining consistency in the purpose of different approaches, the ways they were being used at particular times, and communicating this clearly. This aligns with research by Ormerod (1997, p 53), who found that no inherent paradigmatic conflict was experienced by participants when moving between states commonly associated with the hard and soft paradigms, and that participants '... happily moved from thinking about and debating different points of view to discussing the 'facts' and designing good (hopefully the best) strategies'. Other researchers have also found that '. . . no serious theoretical conflicts arose from using analytic approaches drawn from differing traditions' (Andersen et al, 2006, p 279). Ease in moving between paradigms in this project at HPRB may be related to the personalities of the people involved, however observations by previous authors regarding personal difficulties in changing paradigms mentioned above do have value. What must be considered here is that selection of the key personnel involved is critical.

Reflective diaries were used to analyse changes between the hard and soft paradigms. Paradigm changes were achieved by conscious and explicit decisions about how the world was to be seen, what was to be achieved, and how it was to be communicated. The different paradigms encouraged different areas of emphasis, strengths and weaknesses, and were applicable at different points during the project. For instance, the hard paradigm acted as an anchor, keeping the focus of the project team's exploration directly tied to the needs of implementation. At other times, it was easy to become shortsighted while modelling the strategies, focusing on the technical detail, while ignoring the people and the support they needed for daily decision making. Frequently changing to the soft paradigm allowed for maintenance of a broader perspective on the context. This helped maintain strategic alignment, something which traditional PM does not typically emphasise. At other times action was taken from a neutral perspective, which on reflection could not readily be associated with either paradigm. This supports the idea that a practical middle ground between the paradigms exists, as Pidd (2004a, p 10) suggests.

Other researchers have commented that using hard approaches can ' . . tend to push the decision group in predefined and possibly unhelpful directions . . .', while exclusively using a soft approach '. . . may not force clients to face up to the underlying logic of their situation ...' as the problem can remain expressed in vague terms (Ackerman et al, 1997, p 62). At HPRB it was found that combining hard and soft approaches provided a way not only of encouraging participants to face up to the underlying logic of the situation, but also to consider which underlying logic it is relevant for participants to face up to. 


\section{Reflection on serial and parallel multimethodology}

It is possible to apply multimethodology very effectively, while predominantly only focusing on the practical level of tools and techniques, and good examples of this exist (eg Howick et al, 2006, p 113). However, paradigms should be understood independent of methodologies, tools and techniques. The paradigm that informs action has practical import to how a technique is used. Parallel multimethodology gives the opportunity to adapt the paradigm used in a situation, and to consciously reflect on its applicability to a particular point in an intervention, independent of the technique that is being used at that time. This gives a greater flexibility for technique use, allowing techniques to be interpreted under a different light.

\begin{tabular}{ll}
\hline Serial & Parallel \\
\hline Only one paradigm shift & Multiple paradigm shifts \\
Only one 'triangulation' of perspective against & Multiple 'triangulations' of perspective against \\
a different paradigm & different paradigms \\
Appropriate for stable environments & Appropriate for changing environments \\
Suited to projects with distinct phases & Suited to projects with ongoing processes \\
Suited to efficient delivery & Suited to well-timed delivery \\
Methodology application is prescribed & Methodology application is emergent \\
\hline
\end{tabular}

Table 1: Serial and Parallel approaches to multimethodology

A parallel approach to multimethodology allowed for the qualities of both approaches to be applied throughout the project, as needed. SSM was particularly useful in addressing issues related to barriers created by industry-specific language and terminology usage. PM helped to maintain a focus on deliverables, helped to ensure 'early wins', and encouraged a goal focus during problem exploration when discussion otherwise became sidetracked. A serial approach to multimethodology would had limited effectiveness, as SSM and PM would have been limited to separate project phases. This confirm the results from a study by other researchers, which found that by '. . . cycling between different modelling methods . . . one can achieve benefits that cannot be attained through a staged process that does not permit continuous interaction' (Ackerman et al, 1997, pp 62-63).

Furthermore, if a serial approach had been used, deciding when to change between methodologies would have been problematic given the ongoing environmental turbulence. Multimethodology in series appears most suited to relatively stable situations, such as projects where goals are initially unclear but are expected to remain valid and fixed throughout the life of the project once clearly defined. Such projects often have clearly differentiable project phases, such as in 'front-ending'. However, such an approach can result in aspects of the project being 'finalized' early in the project life cycle, closing off options for development which in a turbulent environment might later become necessary for ensuring project success. By contrast, parallel multimethodology seems suited to turbulent contexts, where it is not clear in advance when particular approaches will be needed, and where project phase changes are stimulated by a changing external context. This approach allows for a dynamic combination of paradigms and their associated methodologies, and is suitable for situations that can not be clearly planned prior to the project, including the bureaucratic process based environments identified by Hassen (1997).

Efficiency of delivery of project objectives is often emphasized in projects set in stable contexts. Serial multimethodology is more suited to these situations, as it is possible to plan necessary actions before initiation or in the early stages of the project. In turbulent or bureaucratic contexts, timing of delivery is often more important. Delivery may instead be required to align with funding cycles, political positioning or to take advantage of emergent opportunities. The frequent change between paradigms in parallel multimethodology is more suited to the demands of these environments, allowing for more responsive, if less efficient, results. There was sufficient time in this project to allow for participants to experiment with changing paradigms and multiple techniques. In a more pressured or intense environment, where efficiency was a stronger value than appropriateness, it may not have been possible to take the time required for parallel multimethodology. Parallel and serial multimethodology are 
Cite as: Pollack, J. (2009). Multimethodology in series and parallel: strategic planning using hard and soft OR. Journal of the Operational Research Society, 60, $156-167$.

suited to different contexts. The differences between these approaches to multimethodology are summarized in Table 1.

Although parallel multimethodology was useful in this project, these research findings are limited by having been applied to only one project, addressing IS strategy development in the public sector. Further development of parallel and serial multimethodology would require application in more projects in different contexts.

\section{Conclusion}

Two distinct approaches to multimethodology have been described. Serial multimethodology has been identified as the more common approach to mixing OR methodologies. This approach is potentially more appropriate in stable situations, where project phases can be identified early, where efficiency is more important than timing, and where the findings from initial project phases are expected to remain valid throughout the life of the project. Serial multimethodology usually involves a movement from soft to hard OR, although exceptions exist.

Parallel multimethodology was examined in the context of an IS strategic planning project involving a combination of SSM and PM, and was found to provide benefits to the project which could likely not have been provided by serial multimethodology. It involves simultaneously using hard and soft OR methodologies, and an emergent approach to mixing methodologies, allowing for paradigms and techniques to be varied in relation to the immediate needs of the context. As such, this approach is more suited to turbulent contexts where it is expected that the demands on the project will change as the project progresses, to projects typified by ongoing processes, and to projects where it is more important to deliver at the right time than as quickly as possible.

It was also found that a single practitioner could use multiple paradigms in a single project. However, when findings by other researchers on the difficulties of swapping between paradigms are taken in light of this research, it suggests that care should be taken when choosing personnel to work on a project involving multiple paradigms. The concepts of parallel and serial multimethodology build on the work of previous authors, including the concept of the oblique use of methods (Flood and Romm, 1997), aspects of TSI (Flood and Jackson, 1991) and Miles' (1988) models of Grafting and Embedding. The significant development presented in this paper relates to the role of the paradigms which informs action. Grafting and Embedding were seen as fundamentally hard and soft, respectively (Miles, 1988, p 59). In contrast, neither multimethodology in series nor in parallel are necessarily aligned with either paradigm, allowing for multiple paradigm changes within a project. These paradigm changes can be made with, or independent of, changes in the techniques used. This provides greater flexibility in how techniques can be used. Both serial and parallel multimethodology provide opportunity to examine the influence of paradigms on practice, as both may involve the oblique application of methods and techniques. Indeed, attention to the paradigm in use is essential in gaining the benefits to be found in using more than one paradigm in a single project.

\section{References}

- Ackerman F, Eden C and Williams T (1997). Modeling for litigation: mixing qualitative and quantitative approaches. Interfaces 27: 48-65.

- Ackermann F, Franco A, Gallupe B and Parent M (2005). GSS for multiorganizational collaboration: reflections on process and content. Group Decis Negotiat 14: 307-331.

- Andersen D, Bryson J, Richardson G, Ackerman F, Eden C and Finn C (2006). Integrating modes of systems thinking into strategic planning education and practice: The Thinking Persons' Institute approach. J Public Affairs Edu 12: 265-293.

- Andersen D and Richardson P (1997). Scripts for group model building. Syst Dyn Rev 13: 107-129.

- Avison D, Eardley W and Powell P (1998). Suggestions for capturing corporate vision in strategic information systems. Omega, Int J Mngt Sci 26: 443-459.

- Avison D and Wood-Harper AT (1990). Multiview: An Exploration into Information 
Systems Development. Blackwell Science: Oxford.

- Belton V, Ackerman F and Shepherd I (1997). Integrated support from problem structuring through alternative evaluation using COPE and VISA. J Multi-Crit Decis Anal 6: 115-130.

- Bond C and Kirkham S (1999). Contrasting the application of soft systems methodology and reflective practice to the development of organizational knowledge and learning - a review of two cases in the UK National Health Service. In: Agarwal R and Prasad J (eds). SIGCPR Conference Proceedings. ACM: New Orleans, USA, pp 242-252.

- Brocklesby J (1997). Becoming multimethodology literate: An assessment of the cognitive difficulties of working across paradigms. In: Mingers $\mathrm{J}$ and Gill A (eds). Multimethodology: The Theory and Practice of Combining Management Science Methodologies. John Wiley \& Sons: Chichester, pp 189-216.

- Brown J, Cooper C and Pidd M (2006). A taxing problem: The complementary use of hard and soft OR in the public sector. Eur J Opl Res 172: 666-679.

- Burrell G and Morgan G (1979). Sociological Paradigms and Organisational Analysis. Gower Publishing: Aldershot, England.

- Calway B (2000). Systems approach for virtual learning development. In: Altman G, Lamp J et al (eds). International Conference on Systems Thinking in Management. CEUR Workshop Proceedings: CEUR-Ws.org, pp 118-123.

- Champion D and Stowell F (2002). Navigating the gap between action and a serving information system. Inform Syst Front 4: 273-284.

- Checkland P (1981). Systems Thinking, Systems Practice. John Wiley \& Sons: Chichester, UK.

- Checkland P and Holwell S (1998). Information, Systems and Information SystemsMaking Sense of the Field. John Wiley \& Sons: West Sussex, England.

- Checkland P and Holwell S (2004). 'Classic' OR and 'Soft' OR-An asymmetric complementary. In: Pidd M (ed). Systems Modelling: Theory and Practice. John Wiley \& Sons: Chichester, pp 45-60.

- Checkland P and Scholes J (1990). Soft Systems Methodology in Action. John Wiley \& Sons: Chichester, UK.

- Cooke-Davies T (2000). Towards improved project management practice. Ph.D. thesis, Leeds Metropolitan University.

- Costello K, Crawford L, Bentley L and Pollack J (2002). Connecting soft systems thinking with project management practice: An organizational change case study. In: Ragsdell G, West D and Wilby J (eds). Systems Theory and Practice in the Knowledge Age. Kluwer Academic/Plunum Publishers: New York.

- Crawford L, Costello K, Pollack J and Bentley L (2003). Managing soft change projects in the public sector. Int J Project Mngt 21: 443-448.

- Day J (2000). Software development as organizational conversation: Analogy as a systems intervention. Syst Res Behav Sci 17: 349-358.

- Fitzgerald B and Howcroft D (1998). Towards dissolution of the IS research debate: From polarization to polarity. J Inform Technol 13: 313-326.

- Flood R and Jackson M (1991). Creative Problem Solving: Total Systems Intervention. John Wiley \& Sons: New York.

- Flood R and Romm N (1997). From metatheory to 'multimethodology'. In: Mingers J and Gill A (eds). Multimethodology: The Theory and Practice of Combining Management Science Methodologies. John Wiley \& Sons: Chichester, pp 291-322.

- Gadamer H (1996). Truth and Method. Translated by Weinsheimer J and Marshall D. Sheed \& Ward: London.

- Gammack J (1995). Modelling subjective requirements objectively. In: Stowell F (ed). Information Systems Provision: The Contribution of Soft Systems Methodology. McGraw-Hill: Berkshire: England, pp 159-185.

- Hassen N (1997). Soft project methodologies-Using mind mapping, and scenario/future mapping techniques in business and public sector projects to develop effective project plans. Proceedings of the 1997 AIPM National Conference. Brisbane, Australia: AIPM, pp 276-286.

- Hobbs B and Miller R (2002). The strategic front end of large infrastructure projects: A process of nesting governance. In: Cleland D, Pinto JK et al (eds). Proceedings of 
the PMI Research Conference. Seattle, USA: PMI.

- Holwell S (2000). Soft systems methodology: Other voices. Syst Pract Act Res 13: 773-798.

- Howick S, Ackerman F and Andersen D (2006). Linking event thinking with structural thinking: Methods to improve client value in projects. Syst Dyn Rev 22: 113-140.

- Jackson M (1997). Critical systems thinking and information systems research. In: Stowell $\mathrm{F}$ and Mingers J (eds). Information Systems: An Emerging Discipline? McGraw-Hill: London, pp 201-238.

- Jackson M (1999). Towards coherent pluralism in management science. J Opl Res Soc 50: 12-22. Jackson M (2000). Systems Approaches to Management. Plenum: New York.

- Kaplan B and Duchon D (1988). Combining qualitative and quantitative methods in information systems research: A case study. MIS Quart 12: 571-586.

- Lai L (2000). An integration of systems science methods and object-oriented analysis for determining organizational information requirements. Syst Res Behav Sci 17: 205-228.

- Lane D and Oliva R (1998). The greater whole: Towards a synthesis of system dynamics and soft systems methodology. Eur J Opl Res 107: 214-235.

- Liu A and Leung M (2002). Developing a soft value management model. Int J Project Mngt 20: 341-349.

- Mathiassen L and Nielsen P (2000). Interaction and transformation in SSM. Syst Res Behav Sci 17: 243-253.

- McQuinn W (2002). Comment on how to conduct an action research study in the domain of information systems development. In: Ragsdell G,West D andWilby J (eds). Systems Theory and Practice in the Knowledge Age. Kluwer Academic/Plenum Publishers: New York.

- Midgley G (1997). Mixing methods: Developing systemic intervention. In: Mingers J and Gill A (eds). Multimethodology: The Theory and Practice of Combining Management Science Methodologies. John Wiley \& Sons: Chichester, pp 249-290.

- Midgley G, Gu J and Campbell D (2000). Dealing with human relations in Chinese systems practice. Syst Pract Act Res 13: 71-96.

- Miles R (1988). Combining 'soft' and 'hard' systems practice: Grafting or embedding? J Appl Syst Anal 15: 55-60.

- Miles R (1992). Combining 'hard' and 'soft' systems practice: Grafting and embedding revisited. Systemist 14: 62-66.

- Mingers J (1995). Using soft systems methodology in the design of information systems. In: Stowell F (ed). Information Systems Provision: The Contribution of Soft Systems Methodology. McGraw-Hill: Berkshire: England, pp 19-49.

- Mingers J (1997). Multi-paradigm Multimethodology. In: Mingers J and Gill A (eds). Multimethodology: The Theory and Practice of Combining Management Science Methodologies. John Wiley \& Sons: Chichester, pp 1-20.

- Mingers J (2003). The paucity of multimethod research: A review of the information systems literature. Inform Syst J 13: 233-249. Mingers J and Brocklesby J (1997). Multimethodology: Towards a framework for mixing methodologies. Omega, Int J Mngt Sci 25: 489-509.

- Munro I and Mingers J (2002). The use of multimethodology in practice-Results of a survey of practitioners. J Opl Res Soc 53: 369-378.

- Neal R (1995). Project definition: The soft-systems approach. Int J Project Mngt 13: 5-9.

- NSW Audit Office (2001). e-government: Use of the Internet and Related Technologies to Improve Public Sector Performance. The Audit Office of New South Wales: Sydney.

- NSW Health (2001). Corporate Plan 2001-2003. NSW Health: NSW.

- NSW Premier's Department (2000). Meeting the Government's Information and Communications Technology Strategic Agenda: Memorandum no. 2000-12. NSW Premier's Department: NSW.

- NSW Premier's Department (2002a). Implementing the Shared Corporate Services Strategy: Circular no. 2002-01. NSW Premier's Department: NSW.

- NSW Premier's Department (2002b). Information Technology-2002 Review of 

soft OR. Journal of the Operational Research Society, 60, $156-167$.

Information Management and Technology Strategic Plans: Circular no. 2002-16. NSW Premier's Department: NSW.

- Office of Information Technology (1997). Information Management \& Technology Blueprint for NSW-A Well-connected Future. Government Information Management Division: Sydney.

- Ormerod R (1995a). Putting soft OR methods to work: Information systems strategy development at Sainsbury's. J Opl Res Soc 46: 277-293.

- Ormerod R (1995b). The role of methodologies in systems strategy development: Reflections on experience. In: Stowell F (ed). Information Systems Provision: The Contribution of Soft Systems Methodology. McGraw-Hill: Berkshire: England, pp 75101.

- Ormerod R (1996). Putting soft OR methods to work: Information systems strategy development at Richards Bay. J Opl Res Soc 47: 1083-1097.

- Ormerod R (1997). Mixing methods in practice: A transformation competence perspective. In: Mingers $\mathrm{J}$ and Gill A (eds). Multimethodology: The Theory and Practice of Combining Management Science Methodologies. John Wiley \& Sons: Chichester, pp 29-58.

- Oura J and Kijima K (2002). Organization design initiated by information system development: A methodology and its practice in Japan. Syst Res Behav Sci 19: 7786.

- Patton M (1990). Qualitative Evaluation and Research Methods. Sage: London.

- Pidd M (2004). Complementarity in systems modelling. In: Pidd M (ed). Systems Modelling: Theory and Practice. John Wiley \& Sons: Chichester, pp 1-20.

- Pidd M (2004). Bringing it all together. In: Pidd M (ed). Systems Modelling: Theory and Practice. John Wiley \& Sons: Chichester, pp 197-207.

- PMI (2004). A Guide to the Project Management Body of Knowledge: Third Edition (PMBOK® Guide). Project Management Institute: PA, USA.

- Pollack J (2005). Project pluralism: Combining the hard and soft paradigms in IS/IT strategy development in the NSW public sector. PhD thesis, University of Technology, Sydney.

- Pollack J (2006). Pyramids or silos: Alternative representations of the systems thinking paradigms. Syst Pract Act Res 19: 383-398.

- Pollack J, Costello K, Crawford L and Bentley L (2006). Systems of information and the development of project management competence. In: Ou $L$ and Turner $R$ (eds). Proceedings of IRNOP VII Project Management Conference. Publishing House of Electronics Industry: Beijing, pp 265-276.

- Ramsay D, Boardman J and Cole A (1996). Reinforcing learning using soft systemic frameworks. Int J Project Mngt 14: 31-36.

- Remington K and Crawford (2004). Illusions of control: Philosophical foundations for Project Management. In: Turner R (ed). Proceedings of IRNOP VI Conference. Turku, Finland: IRNOP.

- Rose J (1997). Soft systems methodology as a social science research tool. Syst Res Behav Sci 14: 249-258.

- Rose J (2002). Interaction, transformation and information systems development-An extended application of Soft Systems Methodology. Inform Technol People 15: 242268.

- Rose J and Haynes M (1999). A soft systems approach to the evaluation of complex interventions in the public sector. J Appl Mngt Stud 8: 199-216.

- Rose J and Meldrum M (1999). Requirements generation for website developments using SSM and the ICDT model. In: Hackney R and Dunn D (eds). Proceedings of the 9th Business Information Technology Conference. Manchester, UK: Manchester Metropolitan University.

- Rosenhead J (1997). Foreword. In: Mingers J and Gill A (eds). Multimethodology: The Theory and Practice of Combining Management Science Methodologies. John Wiley \& Sons: Chichester, pp xii-xiv.

- Sachdeva R, Williams T and Quigley J (2007). Mixing methodologies to enhance the implementation of healthcare operational research. J Opl Res Soc 58: 159-167.

- Stewart R and Fortune J (1995). Application of systems thinking to the identification, avoidance and prevention of risk. Int J Project Mngt 13: 279-286. 
Cite as: Pollack, J. (2009). Multimethodology in series and parallel: strategic planning using hard and soft OR. Journal of the Operational Research Society, 60, $156-167$.

- Taylor M, Moynihan E and Wood-Harper A (1998). Soft systems methodology and systems maintenance. Syst Pract Act Res 11: 419-434.

- Thomas $\mathrm{J}$ and Tjader $\mathrm{J}$ (2000). On learning and control-Competing paradigms or coexisting requirements for managing projects in ambiguous situations? In: Crawford $\mathrm{L}$ and Clarke C (eds). Proceedings of IRNOP IV Conference. Sydney, Australia: IRNOP.

- Turner J and Cochrane R (1993). Goals-and-methods matrix: Coping with projects with ill defined gaols and/or methods of achieving them. Int J Project Mngt 11: 93101.

- Winter M and Checkland P (2003). Soft systems: A fresh perspective for project management. Civil Engineering-Proceedings of ICE 156: 187-192.

- Wolstenholme E (1999). Qualitative vs quantitative modelling: The evolving balance. J Opl Res Soc 50: 422-428.

- Yeo K (1993). Systems thinking and project management-Time to reunite. Int J Project Mngt 11: 111-117.

- Yeo K (2002). Critical failure factors in information system projects. Intl J Project Mngt 20: $241-246$.

- Zhu Z (2000). WSR: A systems approach for information systems development. Syst Res Behav Sci 17: 183-203. 